\title{
Ureter Adenocarcinoma
}

National Cancer Institute

\section{Source}

National Cancer Institute. Ureter Adenocarcinoma. NCI Thesaurus. Code C6155.

Adenocarcinoma that affects the ureter. 